\title{
Adsorptive removal of crystal violet dye by a local clay and process optimization by response surface methodology
}

\author{
Amal Loqman ${ }^{1}$ Brahim El Bali ${ }^{1} \cdot$ Johannes Lützenkirchen $^{2} \cdot$ Peter G. Weidler $^{3}$ • \\ Abdelhak Kherbeche ${ }^{1}$
}

Received: 19 May 2016/Accepted: 24 November 2016/Published online: 26 December 2016

(c) The Author(s) 2016. This article is published with open access at Springerlink.com

\begin{abstract}
The current study relates to the removal of a dye [crystal violet (CV)] from aqueous solutions through batch adsorption experiment onto a local clay from Morocco. The clay was characterized by X-ray diffraction, IR spectroscopy, X-ray fluorescence, scanning electron microscope, Brunauer-Emmett-Teller analysis and Fraunhofer diffraction method. The influence of independent variables on the removal efficiency was determined and optimized by response surface methodology using the Box-Behnken surface statistical design. The model predicted maximum adsorption of $81.62 \%$ under the optimum conditions of operational parameters $\left(125 \mathrm{mg} \mathrm{L}^{-1}\right.$ initial dye concentration, $2.5 \mathrm{~g} \mathrm{~L}^{-1}$ adsorbent dose and time of $43 \mathrm{~min}$ ). Practically, the removal ranges in $27.4-95.3 \%$.
\end{abstract}

Keywords Crystal violet - Clay · Box-Behnken design . Adsorption · Response surface methodology

Brahim El Bali

b_elbali@yahoo.com

1 Laboratory of Catalysis, Materials and Environment, Higher School of Technology, Fez, Morocco

2 Institute für Nukleare Entsorgung (INE), Karlsruher Institut für Technologie (KIT), Hermann-von-Helmholtz-Platz 1, 76344 Eggenstein-Leopoldshafen, Germany

3 Institut für Funktionelle Grenzflächen (IFG), Karlsruher Institut für Technologie (KIT), Hermann-von-HelmholtzPlatz 1, 76344 Eggenstein-Leopoldshafen, Germany

\section{Introduction}

Dyes are harmful pollutants which can cause environmental and ecosystem problems. Their removal from aqueous solution has been widely investigated by the scientists making use of different kinds of adsorbents such as agricultural byproducts, activated carbons, graphene oxide, minerals, polymers, metal oxides, and so forth. Among the variety of dyes, crystal violet (CV) represents one of the most important cationic ones. It is also known as hexamethyl pararosaniline chloride and used in many industrial fields like cosmetic, food, paper-making, printing, leather and textile processing industries (Chen et al. 2008). The latter fields correspond to the biggest users of dyes. In fact, there are more than 10,000 dyes currently used in such industries and over 280,000 tons of the textile dyes are produced annually worldwide (Mass and Chaudhari 2005). The cationic dyes are more toxic than the anionic dyes (Hao et al. 2000). In general, synthetic dyes, which are stable to light, temperature and microbial attack, may also cause allergic dermatitis, cancer and mutation (Rauf et al. 2009; Santhy and Selvapathy 2006). Several technologies have been employed to clean dye containing wastewater, including biological (Javaid et al. 2011) and physicochemical (Qian et al. 2013) procedures, membranes filtration (Kurt et al. 2012), ozonation (Aziz et al. 2012), advanced oxidation (Yasar et al. 2013) and adsorption (Mittal et al. 2012a, b; Lotito et al. 2012). Each of these processes, however, faces certain technical and economical limitations. Adsorption on solid surfaces is an innovative and economical alternative due to the ease of operation and lower prices (Ali 2012; Ali and Gupta 2006). It has been extensively used in the treatment processes of colored waters. Activated carbon has long been used as a standard adsorbent for color removal, but it remains expensive 
(Gupta et al. 2011; Khani et al. 2010; Saleh and Gupta 2012). For this reason, the development of low-cost alternative, reusable, locally available adsorbents has been the focus of recent research. These adsorbents made from natural material require chemical and physical modifications to improve their performance and adsorption capacity (Mittal et al. 2009a, b, 2010; Rehman et al. 2012, 2013). As one example of such cheaper substances, clays are widely used as they are readily available and act both as adsorbents and catalysts (Roulia and Vassiliadis 2005). Owing to their interesting physico-chemical properties (lamellar structure, high surface area and large cation exchange capacity), clays have great potential to fix pollutants, such as heavy metals and organic compounds.

The present research is within the scope of the search for natural and abundant sources of adsorbents as clays and cheaper minerals. More interesting is the fact that the local clay of the present study has not been previously investigated. Indeed, the present work is to characterize it and investigate the adsorption process of crystal violet dye. The second crucial idea of this study was to determine optimum adsorption conditions using the response surface methodology (RSM) based on Box-Behnken statistical design. The RSM is based on a combination of mathematical and statistical techniques. It has been employed to analyze the influences of main factors, as well as their effect on dependent variables during the experiments. Therefore, optimum conditions for desired responses can be predicted (Chowdhury et al. 2011, 2013; Hamsaveni et al. 2001; Hasan et al. 2009; Muhamad et al. 2013). The effects of initial dye concentration, adsorbent dose and contact time on the removal efficiency were evaluated and were considered as the operational variables in the present study.

\section{Materials and methods}

\section{Preparation and characterization of the local clay}

A green colored clay was obtained from the region Berkane, north eastern Morocco. The adsorbent was crushed, and sieved to a particle size less than $63 \mu \mathrm{m}$, and dried at $100{ }^{\circ} \mathrm{C}$ for $24 \mathrm{~h}$. The specific surface area of the adsorbent was measured by the Brunauer-Emmett-Teller (BET) method with an AUTOSORB-1 (Quantachrome Corporation). The mineralogical phase characterization was carried out by quantitative X-ray diffraction (XRD). Samples were run on a Bruker D8 Advance with $\mathrm{Cu}-\mathrm{K} \alpha, 2$ radiation $(0.15418 \mathrm{~nm})$ equipped with a Lnyxeye $(\mathrm{C})$ stripe detector $(2 \theta)$ from $5^{\circ}$ to $65^{\circ}$ with a step width of $0.024^{\circ}$ and $168 \mathrm{~s}$ counting time per step. The divergence slit was set to a constant footprint size of $12 \mathrm{~mm}$ of the beam on the sample. The particle size was determined by Fraunhofer method using a Beckman Coulter LS Particle Size Analyzer. The presence of functional groups present on the local clay was examined by Fourier transform infrared (FTIR in the range of $400-4000 \mathrm{~cm}^{-1}$ ) spectroscopy method using a FTIR spectrometer (VERTEX 70). The surface elemental composition of the adsorbent used in this study was determined using an EDX detector in combination with a field emission scanning electron microscope (Quanta 650 FEG, ESEM-Fa FEI). Electrophoretic mobilities of the local clay were determined by a BrookhavenPALS apparatus at room temperature. $\mathrm{pH}$-measurements involved calibration of the $\mathrm{pH}$-measurement device (Orion pH-meter. and Thermo-science Fisher electrode) with four commercial buffers.

The local clay was used as received without any pretreatment in the adsorption experiments.

\section{Dye solution}

$\mathrm{CV}$ was purchased from Sigma-Aldrich. The structures and some characteristics of CV dye (Ahmad 2009) are illustrated in Table 1.

The stock solution of CV dye was prepared by dissolving $1 \mathrm{~g}$ of dye in $1 \mathrm{~L}$ of distilled water. Different concentrations of $\mathrm{CV}$ dye used in this experiment were prepared by diluting the stock solution with distilled water. Separated analyses were done at $\lambda_{\max }=590 \mathrm{~nm}$ using a UV-Visible spectrophotometer (VR-2000).

\section{Experimental procedure}

Batch adsorption experiments were carried out at room temperature, using a jar test assembly. The latter consists in contacting and stirring at $200 \mathrm{rpm}$ jars containing $200 \mathrm{ml}$ suspensions of the CV solutions of different known total concentrations (50, 100 and $150 \mathrm{mg} \mathrm{L}^{-1}$ ) with known adsorbent masses (1, 5, 2 and $2.5 \mathrm{~g}$ ). Samples were taken for analysis from each jar at 15, 30 and $45 \mathrm{~min}$, respectively. UV-Vis. analysis, employing the spectrophotometer VR-2000, is used to determine residual concentrations of $\mathrm{CV}$ after solid-liquid separation. The chosen wavelength corresponds to the maximum absorbance of the sample and is at $\lambda=590 \mathrm{~nm}$. The residual dye content was determined by interpolation using the previously established calibration curve. The study of the adsorption of a compound on an adsorbent allows us to examine the influence of the contact time on its retention. This study was carried out to determine the adsorbed quantities of the dye from its initial contact until dynamic equilibrium. To determine the waiting time for dynamic equilibrium, a preliminary adsorption experiment was carried out which involved introducing a precisely weighed quantity of adsorbent into a volume of $500 \mathrm{~mL}$ of solution containing dye at a 
Table 1 Characteristics of (CV)

\begin{tabular}{llllll}
\hline Name & Chemical structure & Molecular formula & $\mathrm{Mw}\left(\mathrm{g} \mathrm{mol}^{-1}\right)$ & $\mathrm{Nature}$ & $\lambda \mathrm{max}(\mathrm{nm})$ \\
\hline Crystal violet (methyl violet 10B) & & $\mathrm{C}_{25} \mathrm{H}_{30} \mathrm{ClN}_{3}$ & 407,98 & $\mathrm{Cationic}_{590}$ \\
& &
\end{tabular}

concentration of $50 \mathrm{mg} \mathrm{L}^{-1}$. Subsequently samples were taken at well-defined (short) time intervals (every $2 \mathrm{~min}$ ). The colored solution was separated from the adsorbent by centrifugation at $3400 \mathrm{rpm}$ and analyzed as specified above. From the results of these preliminary tests, the time intervals were fixed at 15,30 , and $45 \mathrm{~min}$.

The percent (\%) CV removal was calculated using Eq. (1):

$\%$ Removal $=100\left(c_{0}-c_{\mathrm{e}}\right) / c_{0}$,

where $C_{0}$ and $C_{\mathrm{e}}$ are the initial and final concentration $\left(\mathrm{mg} \mathrm{L}^{-1}\right)$, respectively.

\section{Design of experiment and optimization}

Box-Behnken design for Response surface methodology is used by experimentalists to examine the relationship between one or more dependent response variables and a set of quantitative experimental factors (independent variables). In the present study this design was utilized to determine the effect of three factors (initial dye concentration, adsorbent dosage and contact time) on the removal efficiency of CV dye using a local clay over three levels. The ranges and levels of the experimental parameters are depicted in Table 2. The total number of experiments can be calculated using Eq. (2):

Table 2 Coded and real values of the operational parameters for Box-Behnken statistical design

\begin{tabular}{llll}
\hline Factors & \multicolumn{3}{l}{ Coded and real value } \\
\cline { 2 - 4 } & -1 & 0 & +1 \\
\hline Initial concentration $\left(\mathrm{mg} \mathrm{L}^{-1}\right) X_{1}$ & 50 & 100 & 150 \\
Adsorbent dose $\left(\mathrm{mg} \mathrm{L}^{-1}\right) X_{2}$ & 1.5 & 2 & 2.5 \\
Contact time (min) $X_{3}$ & 15 & 30 & 45 \\
\hline
\end{tabular}

$N=2^{F}+2 F+\chi_{0}$

where $N, F$ and $\chi_{0}$ are the number of experimental runs, the factor number and the number of replicates at the central point, respectively. In the present study, the values of $N, F$ and $\chi_{0}$ were 17, 3 and 5, respectively (Soltani et al. 2013). The relationship between coded and real values of variables can be measured using to the following Eq. (3) (Myers and Montgomery 2002; Poroch-Seritan et al. 2011; Zarei et al. 2010):

$x_{0}=\left(X_{i}-X_{0}\right) / \delta X$,

$X_{0}$ and $X_{i}$ represent the coded and real values of the independent variables, respectively. However, $X_{0}$ and $\delta X$ are the values of $X_{i}$ at the central point and step change, respectively.

A second-order polynomial response surface model for the fitting of experimental data can be described using Eq. (4):

$$
\begin{aligned}
\gamma= & b_{\mathrm{o}}+\sum_{i=1}^{n} b_{i} x_{i}+\sum_{i=1}^{n}\left(b_{i i} x_{i i}^{2}\right) \\
& +\sum_{i=1}^{n-1} \sum_{j=i+1}^{n} b_{i j} x_{i} x_{j},
\end{aligned}
$$

where $\gamma$ is the predicted response (removal efficiency $\%$ ), $x_{i}$ denotes independent variables, $b_{\mathrm{o}}$ is a constant offset term and $b_{i}$ are linear coefficients. Furthermore, $b_{i i}$ and $b_{i j}$ are the regression coefficients for the quadratic and interaction effects, respectively (Amenaghawon et al. 2013; Khajeh 2009; Shakeel et al. 2014). The values of these coefficients $\left(b_{i}, b_{i i}\right.$ and $\left.b_{i j}\right)$ are determined by Eq. (5):

$b=\left(X^{T} X\right)_{-1} X^{T} Y$,

where $b$ is a vector of coefficients, $X$ is the design matrix for coded levels of variables and $Y$ represents the vector of response (Khayet et al. 2011; Poroch-Seritan et al. 2011). 
Fig. 1 FT-IR spectra of the local clay

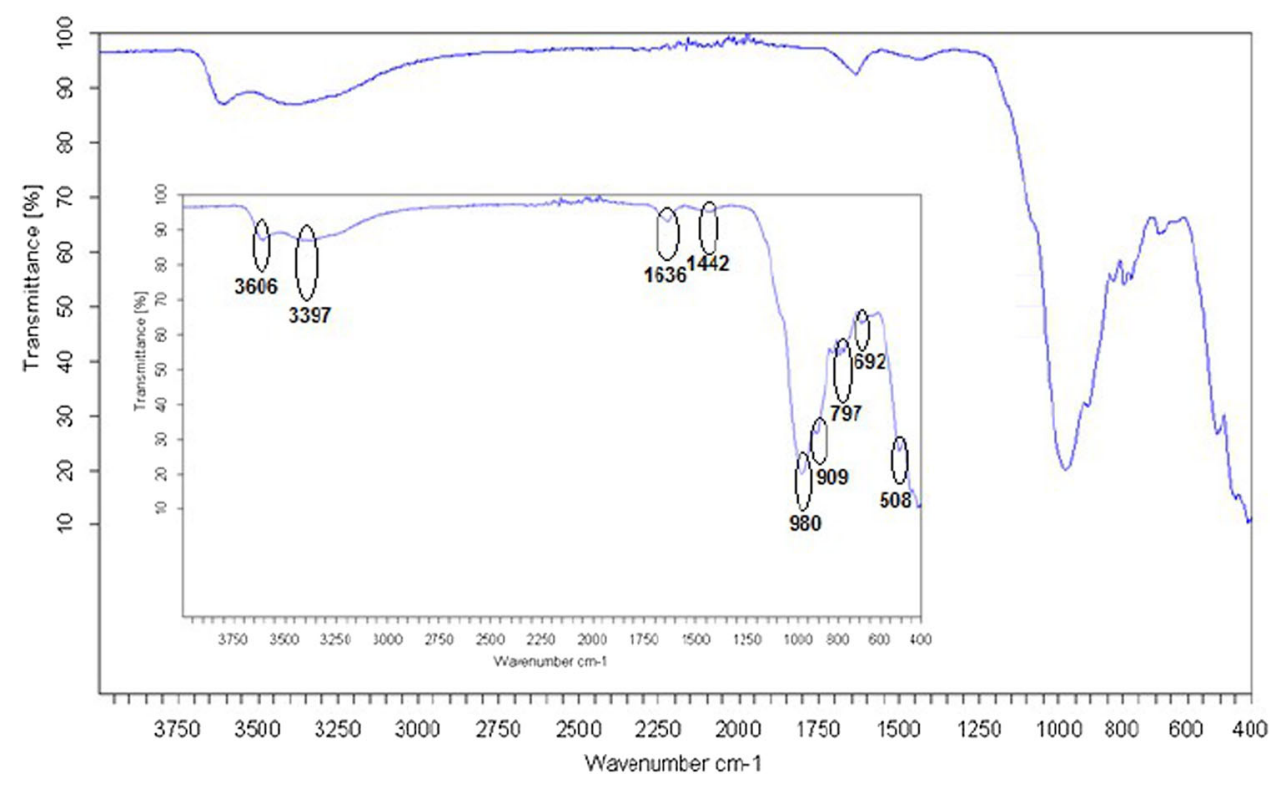

\section{Results and discussion}

\section{Characterization of the adsorbent material}

FT-IR analysis was used to evaluate the role of functional groups situated on the surface of adsorbent in the adsorption process. The FTIR spectrum of the local clay (Fig. 1) showed several absorption bands, the peak at $3606 \mathrm{~cm}^{-1}$ attributed to the vibration band of structural hydroxyl groups. Broad bands at 3397 and $1636 \mathrm{~cm}^{-1}$ show the axial deformation and angular deformation of the hydration water (Iliescu et al. 2014). The peaks centred at 797 and $1442 \mathrm{~cm}^{-1}$ correspond to $\mathrm{Si}-\mathrm{O}$ in $\mathrm{SiO}_{2}$ and $\mathrm{CO}_{3}$, stretching vibration, respectively, whereas the bands at $508 \mathrm{~cm}^{-1}$ represent the $\mathrm{Si}-\mathrm{O}-\mathrm{Si}$ vibrations of quartz. The vibration bands at 692 and $909 \mathrm{~cm}^{-1}$ for the local clay are assigned to the deformations of $\mathrm{Si}-\mathrm{O}-\mathrm{Al}$ and $\mathrm{Al}-\mathrm{OH}$, respectively.

Electrokinetic experiments were carried out to provide information about the charge state of the particles. Figure 2 shows that the clay bears a negative net charge within the shear plane above $\mathrm{pH} 2$. This is typical of many clay particles and explained by the permanent negative charge caused by isomorphous substitution.

SEM-EDX analyses yielded the results summarized in Table 3 . The values given represent the average and standard deviation of five distinct measurement points. Sodium was found in only one spot.

The main components typical of the local clay are $\mathrm{Si}$ and Al. Minor components like $\mathrm{K}, \mathrm{Mg}, \mathrm{Fe}$ or $\mathrm{Ti}$ are also expected for natural clay samples. The carbon contribution could be from accessory minerals (Calcite) or adventitious carbon. The iron present gives the clay its greenish color.

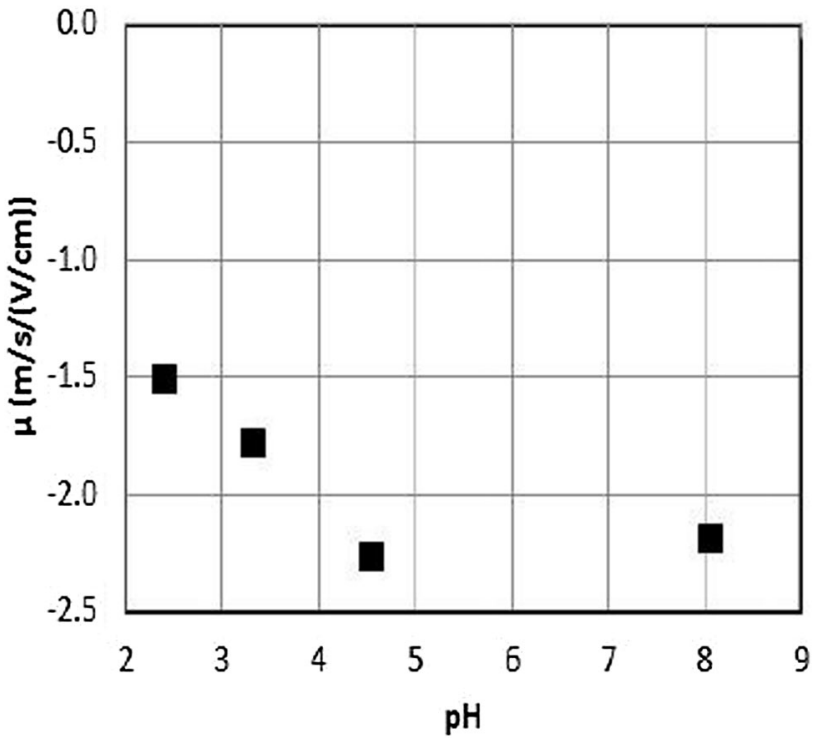

Fig. 2 Electrophoretic mobility of the local clay as a function of $\mathrm{pH}$ in MilliQ-water. $\mathrm{pH}$ adjustment was done using $\mathrm{NaOH}$ and $\mathrm{HCl}$ solutions

The morphological structure of the adsorbent was characterized by scanning electron microscopy. The SEM images of the local clay taken at different magnifications in Fig. 3a-e show that it is a heterogeneous material consisting of particles of irregular shapes having considerable layers.

The clay is well crystallized as can be shown its X-Rays powder diffractogram depicted on Fig. 4. The mineral generally consists of $\mathrm{SiO}_{2}$ plus minor additional components, mainly represented by the band around $2 T=2 \theta$ which we could not assign. The main oxides based on 
Table 3 Atom percent analysis results, data collected at five distinct spots, standard deviation*10

\begin{tabular}{lllllllll}
\hline $\mathrm{Al}$ & $\mathrm{C}$ & $\mathrm{Fe}$ & $\mathrm{K}$ & $\mathrm{Mg}$ & $\mathrm{Na}$ & $\mathrm{O}$ & $\mathrm{Si}$ \\
\hline $6.9(8)$ & $10.5(33)$ & $1.3(4)$ & $2.5(7)$ & $1.4(2)$ & $0.2(-)^{\mathrm{a}}$ & $60.7(19)$ & $16.5(15)$ & $0.2(1)$ \\
\hline
\end{tabular}

${ }^{a}$ Not determined

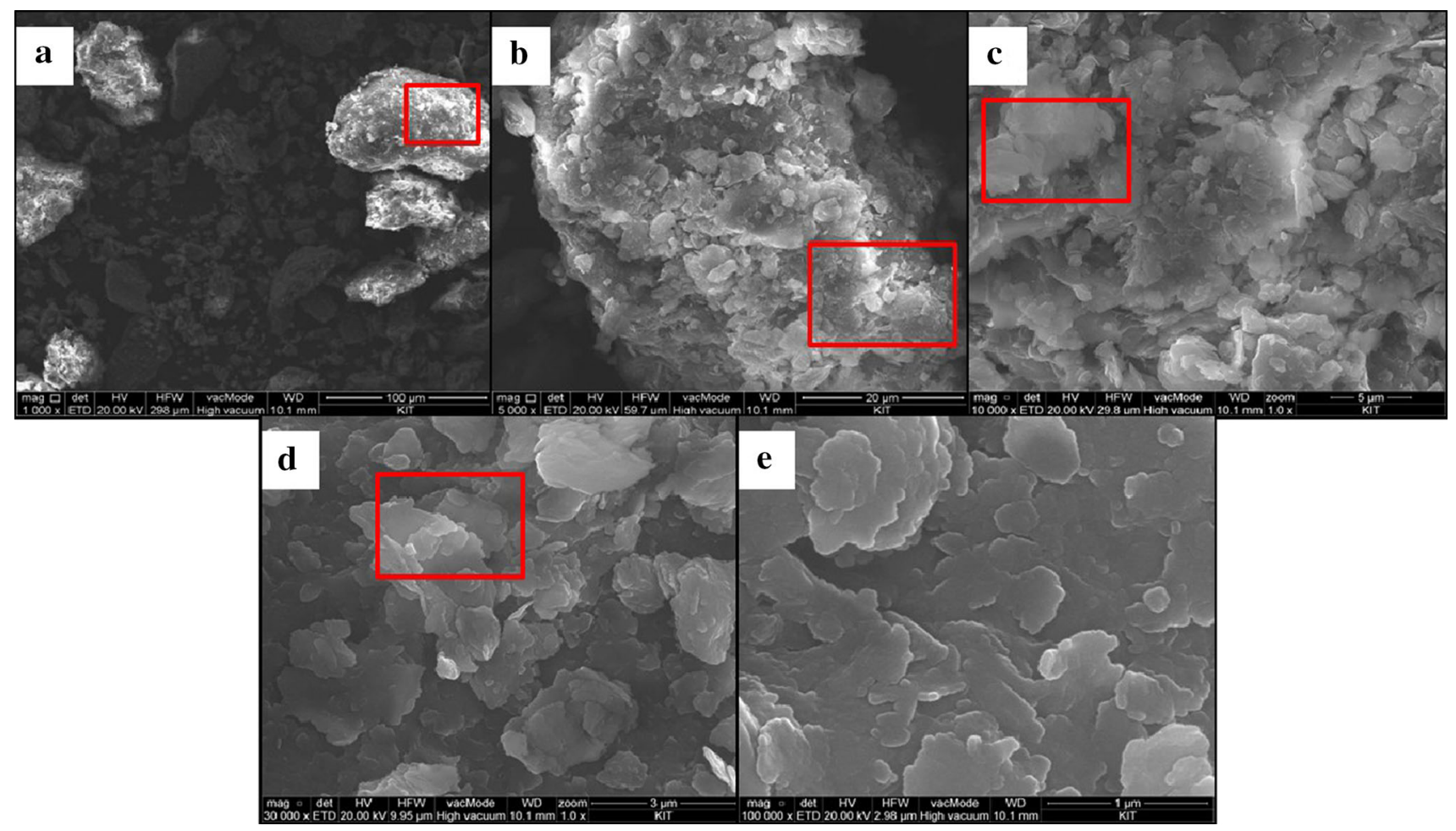

Fig. 3 SEM images of the local clay

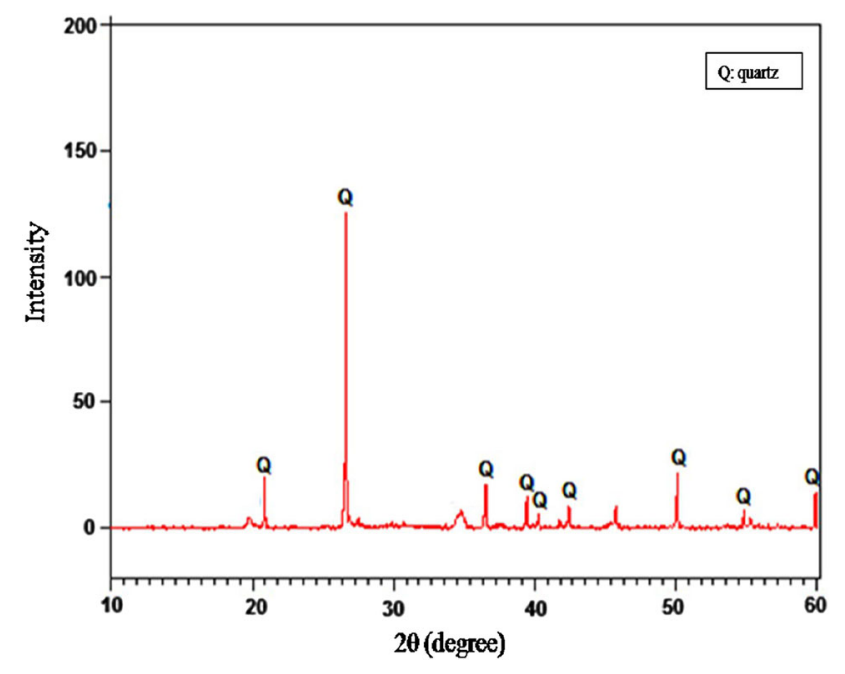

Fig. 4 XRD patterns of local clay

elemental analysis of the local clay composition (Table 4) are silica $(63 \%)$, aluminum $(\approx 15 \%)$ and iron $(\approx 5 \%)$. These oxides are important as possible participants in dye- adsorption. The clay also includes significant quantities of unburned carbon $(\approx 8 \%)$ representing further adsorption sites for dyes (Ahmaruzzaman 2010). Moreover, it was found to contain oxides of exchangeable cations such as $\mathrm{Ca}, \mathrm{Mg}, \mathrm{Na}$ and $\mathrm{K}$ with varying percentage. The results agree well with the EDX data given in Table 3.

The specific surface area and total pore volume of the local clay were determined as $38.08 \mathrm{~m}^{2} \mathrm{~g}^{-1}$ and $8.75 \mathrm{~cm}^{3} \mathrm{~g}^{-1}$, respectively, a bit larger than that of Graphene Oxide (32 $\mathrm{m}^{2} \mathrm{~g}^{-1}$ ) (Mittal et al. 2010). We included in Table 5 features of the present clay compared to those of some other adsorbents reported in the literature.

Figure 5 shows a full gas adsorption and desorption curve $\left(\mathrm{N}_{2}\right)$. The hysteresis for $p / p_{0}>\times 0.5$ supports the presence of some porosity. The phenomena might result from pore shape irregularity. In fact, if one can relate this to water-sol interactions, the hysteresis effect can be attributed to four main causes: (1) geometric nonuniformity of individual pores, which results from the "ink Bottle" effect, (2) different spacial connectivity between the pores during drying and wetting processes, (3) variation in 
Table 4 Chemical composition of VT

\begin{tabular}{llllllllll}
\hline Constituent & $\mathrm{SiO}_{2}$ & $\mathrm{Al}_{2} \mathrm{O}_{3}$ & $\mathrm{Fe}_{2} \mathrm{O}_{3}$ & $\mathrm{CaO}$ & $\mathrm{MgO}$ & $\mathrm{SO}_{3}$ & $\mathrm{~K}_{2} \mathrm{O}$ & $\mathrm{Na}_{2} \mathrm{O}$ & $\mathrm{LI}^{\mathrm{a}}$ \\
\hline Wt. $(\%)$ & 63.00 & 14.85 & 5.02 & 1.11 & 2.65 & 0.06 & 5.14 & 0.06 & 7.8 \\
\hline
\end{tabular}

${ }^{a}$ Loss on ignition

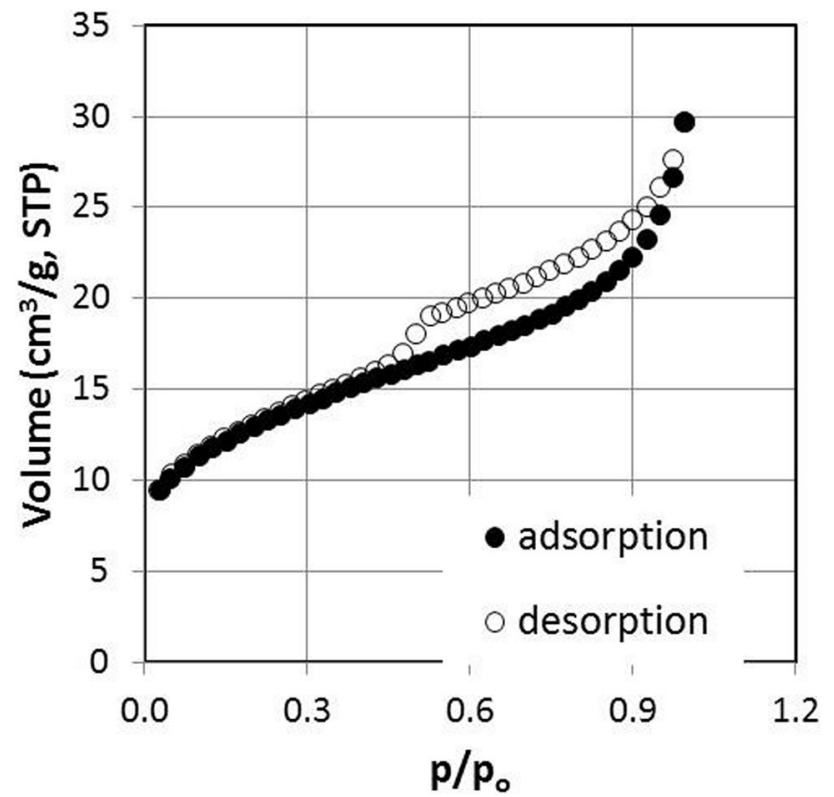

Fig. 5 Complete $\mathrm{N}_{2}$ adsorption and desorption curve for local clay

liquid-solid contact angle, and (4) air entrapment (Marshall et al. 1996) (Table 5).

The particle size, shape and distribution have been reported to be a very important property in determining the industrial uses of clays (Murray 2000). For this purpose, Beckman Coulter LS Particle Size Analyzer was used to determine the granulometric parameters $d_{10}, d_{50}$ and $d_{90}$ of the local clay. The cumulative and differential particle size distributions of this material are presented in Fig. 6 resulting in $2.10,25.47$ and $110.10 \mu \mathrm{m}$, respectively, for $d_{10}, d_{50}$ and $d_{90}$.

\section{Response surface modeling}

We have adopted the Box-Behnken design for investigating the individual and mutual effects of the factors screened concerning the adsorption of $\mathrm{CV}$ dye by the local clay from aqueous solution. The $(\%)$ removal of $\mathrm{CV}$ in this study was observed in the range of 27.42-95.30\% (Table 6). This result can be compared to values obtained on other absorbents: Biomass of Nostoc linckia (39, 3-72\%) (Sharma et al. 2011), Biomass of Calotropis procera (57, 76-80.48\%) (Hazrat and Shah 2008). Overall, local clay can be considered as an efficient adsorbent for treating colored waters.
Regression between the dependent variable (dye removal) and the corresponding coded values of the three different independent variables yields the following quadratic model:

$$
\begin{aligned}
\gamma \%= & 73.29-20.63 x_{1}+14.83 x_{2}+10.17 x_{3}+4.67 x_{1}^{2} \\
& -8.26 x_{2}^{2}-9.92 x_{3}^{2}+8.35 x_{1} x_{2}+6.86 x_{1} x_{3} \\
& +2.09 x_{2} x_{3} .
\end{aligned}
$$

The analysis of variance (ANOVA) and $F$ test are considered to be essential to examine the significance and adequacy of the second-order regression models (Khataee et al. 2011). The results of such analysis are summarized in Table 7. The model was found to be highly significant, as evident from the Fisher's $F$ test $\left(F_{\text {model }}=281.53\right)$ with a very low probability value $\left(P_{\text {model }}<0.0001\right)$. Furthermore, the comparison of the critical $F$ value $\left(F_{0.05,9,9}=3.179\right)$ with the calculated $F$ value $\left(F_{\text {model }}=281.53\right)$ showed a critical $F$ value of less than the calculated $F$ value, suggesting that most of the variation in the response can be explained by the quadratic model equation (Liu et al. 2004; Sen and Swaminathan 2004; Yetilmezsoy et al. 2009).

Figure $7 \mathrm{a}$ shows a good agreement between the predicted and observed values with a high coefficient of determination $\left(R^{2}=0.997\right)$. It reveals that most of the data variation $(99.7 \%)$ was explained by the regression model and that the model explains $97.8 \%$ of the variations in dye removal. Besides, the adjusted $R^{2}$ corrects the value of $R^{2}$ for sample size and the number of terms in the applied model (Khataee and Dehghan 2011; Khataee et al. 2012). In our case, the value of adjusted multiple correlation coefficient (adj. $R^{2}=0.993$ ) was found to be smaller than $R^{2}$. This suggests that the observed results are in reasonable agreement with the predicted results (Khataee et al. 2011; Soltani et al. 2014).

Furthermore, the obtained $P$ value implies importance of each factor for removal efficiency of $\mathrm{CV}$ dye. Therefore, it can be seen from Table 8 that all model terms such as linear $\left(X_{1}, X_{2}\right.$ and $\left.X_{3}\right)$ quadratic $\left(x_{1}^{2}, X_{2}^{2}\right.$ and $\left.X_{3}^{2}\right)$ and interactive effects $\left(X_{1} X_{2}, X_{2} X_{3}\right.$ and $\left.X_{1} X_{3}\right)$ are statistically significant.

The statistical results (Table 8) further suggested that the relative order of operational parameters for adsorption of CV can be dye concentration $\left(F\left(X_{1}\right)=1185.98\right)>$ adsorbent dosage $\left(F\left(X_{2}\right)=613.39\right) \quad>$ contact time $\left(F\left(X_{3}\right)=288.04\right)$, making the initial dye concentration the 
Table 5 Comparison of BET surface area of local clay with other adsorbents

\begin{tabular}{lll}
\hline Adsorbents & BET surface area $\left(\mathrm{m}^{2} \mathrm{~g}-{ }^{1}\right)$ & References \\
\hline Treated saw dust (SD) & 0.3742 & (Mane and Babu 2011) \\
Kaolin & 13.69 & (Nandi et al. 2009) \\
Vermiculite & 15.2 & (Padilla-Ortega et al. 2013) \\
Graphene oxide & 32 & (Mittal et al. 2010) \\
Modified nanoclay & 11.478 & (Hassani et al. 2015) \\
Local clay & 38.08 & Present study \\
\hline
\end{tabular}

parameter exhibiting the most significant effect on dye removal through the adsorption process. On the other hand, random dispersal of the residuals can be seen in the plots of

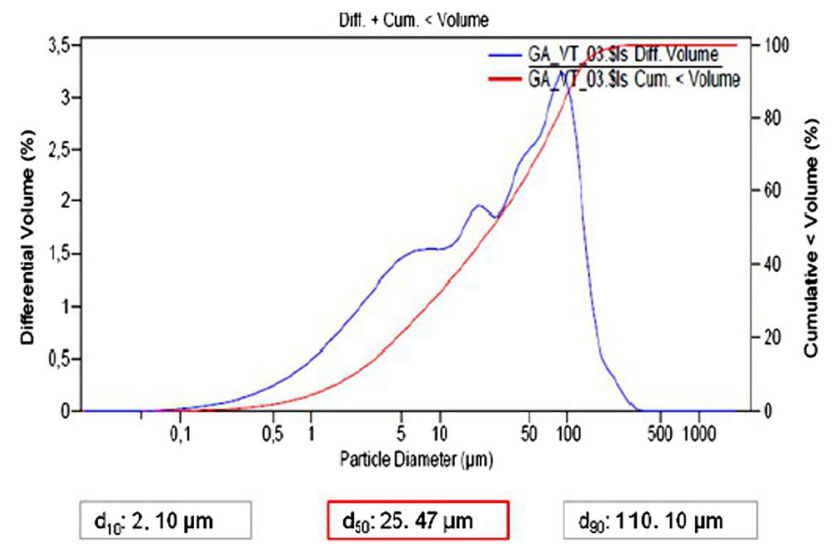

Fig. 6 Particle size distribution of the local clay residuals versus predicted dye removal (\%), Fig. 7b, implying good agreement between predicted and experimental decolorization efficiency.

The three-dimensional (3D) response surface plots and corresponding contour plots provide information on the impact of interactions terms and their effects on the dependent variable (Adinarayana and Ellaiah 2002; Wu et al. 2009). Figure 8 illustrates the response surface for mutual effects relating to dye concentration and adsorbent dosage. As depicted, increasing adsorbent dosage along with decreasing dye concentration led to increasing dye removal (\%) when the contact time was constant at $30 \mathrm{~min}$. Dye removal increased with increase in adsorbent dosage and the two showed statistically significant an identical relationship (Eq. 6) as could be expected. Increased dye removal with increasing amount of adsorbent is related to the larger reactive surface area and more active sites for the adsorption of adsorbate molecules (Kousha et al. 2012).

Table 6 Box-Behnken design for three independent variables with the observed and predicted responses of CV dye removal (\%)

\begin{tabular}{|c|c|c|c|c|c|c|c|c|}
\hline \multirow[t]{3}{*}{ Run order } & \multicolumn{3}{|l|}{ Factors } & \multicolumn{5}{|c|}{ Response } \\
\hline & \multirow{2}{*}{$\begin{array}{l}\text { Coded parameters } \\
X_{1}\end{array}$} & \multirow{2}{*}{$\begin{array}{l}\text { Real parameters } \\
X_{2}\end{array}$} & \multirow{2}{*}{$\begin{array}{l}\text { Removal (\%) } \\
X_{3}\end{array}$} & & & & & \\
\hline & & & & $X_{1}$ & $X_{2}$ & $X_{3}$ & Observed & Predicted \\
\hline 1 & 0 & 0 & 0 & 100 & 2.0 & 30 & 74.01 & 73.29 \\
\hline 2 & 0 & -1 & +1 & 100 & 1.5 & 45 & 46.85 & 48.37 \\
\hline 3 & +1 & 0 & -1 & 150 & 2.0 & 15 & 28.42 & 30.40 \\
\hline 4 & +1 & +1 & 0 & 150 & 2.5 & 30 & 72.74 & 72.26 \\
\hline 5 & -1 & -1 & 0 & 50 & 1.5 & 30 & 83.37 & 83.85 \\
\hline 6 & 0 & 0 & 0 & 100 & 2.0 & 30 & 73.68 & 73.29 \\
\hline 7 & 0 & 0 & 0 & 100 & 2.0 & 30 & 72.07 & 73.29 \\
\hline 8 & -1 & 0 & +1 & 50 & 2.0 & 45 & 93.97 & 91.99 \\
\hline 9 & 0 & +1 & -1 & 100 & 2.5 & 15 & 59.20 & 57.69 \\
\hline 10 & -1 & +1 & 0 & 50 & 2.5 & 30 & 95.30 & 96.82 \\
\hline 11 & +1 & 0 & +1 & 150 & 2.0 & 45 & 64.43 & 64.44 \\
\hline 12 & 0 & 0 & 0 & 100 & 2.0 & 30 & 73.30 & 73.29 \\
\hline 13 & 0 & -1 & -1 & 100 & 1.5 & 15 & 32.67 & 32.21 \\
\hline 14 & 0 & +1 & +1 & 100 & 2.5 & 45 & 81.74 & 82.20 \\
\hline 15 & -1 & 0 & -1 & 50 & 2.0 & 15 & 85.38 & 85.37 \\
\hline 16 & 0 & 0 & 0 & 100 & 2.0 & 30 & 73.41 & 73.29 \\
\hline 17 & +1 & -1 & 0 & 150 & 1.5 & 30 & 27.42 & 25.90 \\
\hline
\end{tabular}


Similar behavior has been reported by Mark Daniel et al. (2013) in the case of the adsorption of Eriochrome Black T (EBT) onto activated carbon prepared from waste rice hulls.

Contact time plays an important role in the treatment processes of colored waters (Kousha et al. 2012). Figure 9 depicts the surface plot of removal of $\mathrm{CV}$ as a function of contacts time and adsorbent dosage. Removal of $\mathrm{CV}$ is enhanced as contact time and adsorbent dosage increase. The combined effect of adsorbent dosage and contact time were positive and statistically significant as also revealed by the contour lines and Table 7 . Maximum dye removal $(>83 \%)$ was observed at constant dye concentration $100 \mathrm{mg} \mathrm{L}^{-1}$.

Figure 10 depicts the combination of the two parameters: contacts time and initial dye concentration, with the adsorbent dosage at central point considered to be $2 \mathrm{~g} \mathrm{~L}^{-1}$. It can be seen that the lowest percent removal is optimized in higher concentrations of dye $150 \mathrm{mg} \mathrm{L}^{-1}$. Dye removal of $\mathrm{CV}$ was increased with decreasing dye concentration from 50 to $150 \mathrm{mg} \mathrm{L}^{-1}$. This can be explained by saturation of adsorptive sites on the surface of the clay (Deniz and Saygideger 2010). Similarly, Feng et al. (2011) observed that dye removal of methylene blue by their adsorbent increases when decreasing the dye concentration

Table 7 Analysis of variance (ANOVA) for the adsorption of CV onto VT

\begin{tabular}{llllll}
\hline Source & $\begin{array}{l}\text { Sum of } \\
\text { squares }\end{array}$ & $\begin{array}{l}\text { Degree of } \\
\text { freedom }\end{array}$ & $\begin{array}{l}\text { Mean } \\
\text { square }\end{array}$ & $F$ value & $P$ value \\
\hline Regression & 7271.39 & 9 & 807.93 & 281.53 & $<0.0001$ \\
Residuals & 20.09 & 7 & 2.87 & - & - \\
Lack of fit & 17.92 & 3 & 5.97 & 10.99 & 0.0211 \\
Pure error & 2.17 & 4 & 0.54 & - & - \\
Total & 7291 & 16 & - & - & - \\
\hline
\end{tabular}

$R^{2}=0.9972$, Adjusted $R^{2}=0.9937$ from 450 to $100 \mathrm{mg} \mathrm{L}^{-1}$. Statistically, the interactive effect of dye concentration and contact time is positive and significant, according to contour lines and multiple regression (Eq. 6).

\section{Conclusion}

The performance of local clay for removal of CV dye from aqueous solution was modeled and optimized using response surface methodology by the Box-Behnken model. Experiments were made as a function of three important operational parameters including initial dye concentration, adsorbent dose and contact time. The statistical analysis results suggested that a second-order polynomial regression model could properly interpret the experimental data with a coefficient of determination $R^{2}$ value 0.997 and Fisher $F$ value of 281.53 . The first-order main effects of the independent variables $\left(X_{1}, X_{2}\right.$ and $\left.X_{3}\right)$ were relatively more significant than their respective quadratic effects $\left(X_{1}^{2}, X_{2}^{2}\right.$

Table 8 Estimated regression coefficient and corresponding $F$ and $P$ values obtained during Box-Behnken design for the adsorption of $\mathrm{CV}$ onto VT

\begin{tabular}{lclrc}
\hline Coefficient & Coefficient estimate & Standard error & $F$ value & $P$ value \\
\hline $\mathrm{b}_{0}$ & 73.29 & 0.76 & 281.53 & $<0.001$ \\
$\mathrm{~b}_{1}$ & -20.63 & 0.60 & 1185.98 & $<0.001$ \\
$\mathrm{~b}_{2}$ & 14.83 & 0.60 & 613.39 & $<0.001$ \\
$\mathrm{~b}_{3}$ & 10.17 & 0.60 & 288.04 & $<0.001$ \\
$\mathrm{~b}_{12}$ & 8.35 & 0.85 & 97.12 & $<0.001$ \\
$\mathrm{~b}_{13}$ & 6.86 & 0.85 & 65.50 & $<0.001$ \\
$\mathrm{~b}_{23}$ & 2.09 & 0.85 & 6.09 & 0.0430 \\
$\mathrm{~b}_{11}$ & 4.67 & 0.83 & 19.82 & 0.0030 \\
$\mathrm{~b}_{22}$ & -8.26 & 0.83 & 113.49 & $<0.001$ \\
$\mathrm{~b}_{33}$ & -9.92 & 0.83 & 144.33 & $<0.001$ \\
\hline
\end{tabular}

Fig. 7 The plot of predicted versus experimental dye removal of $\mathrm{CV}$ (a) and residual (b)

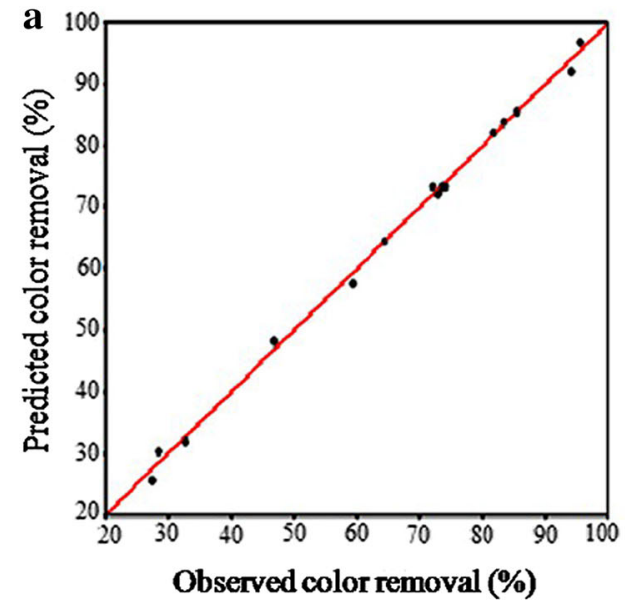



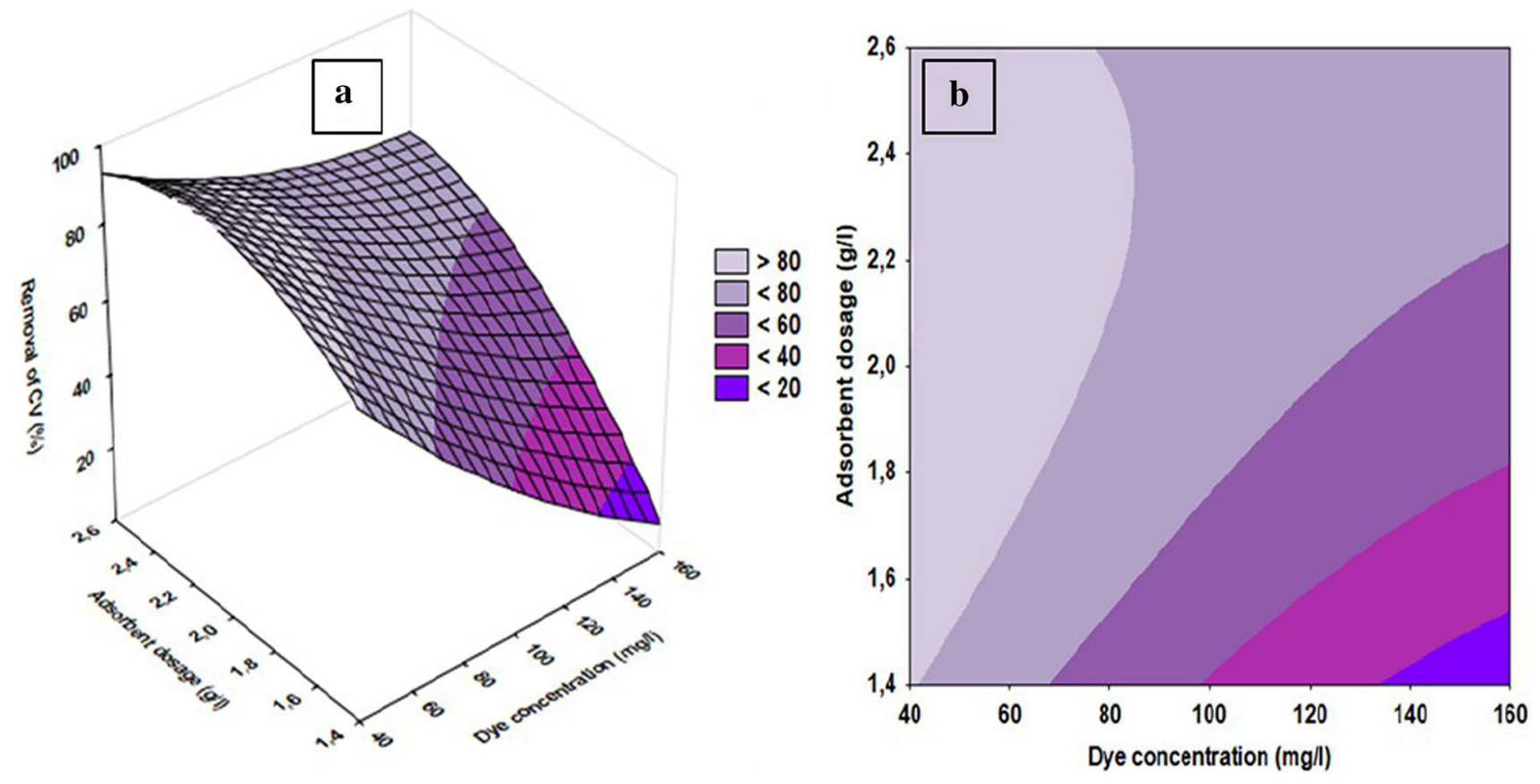

Fig. 8 The response surface plot (a) and corresponding counter plot (b) for the interactive effect of dye concentration and adsorbent dosage
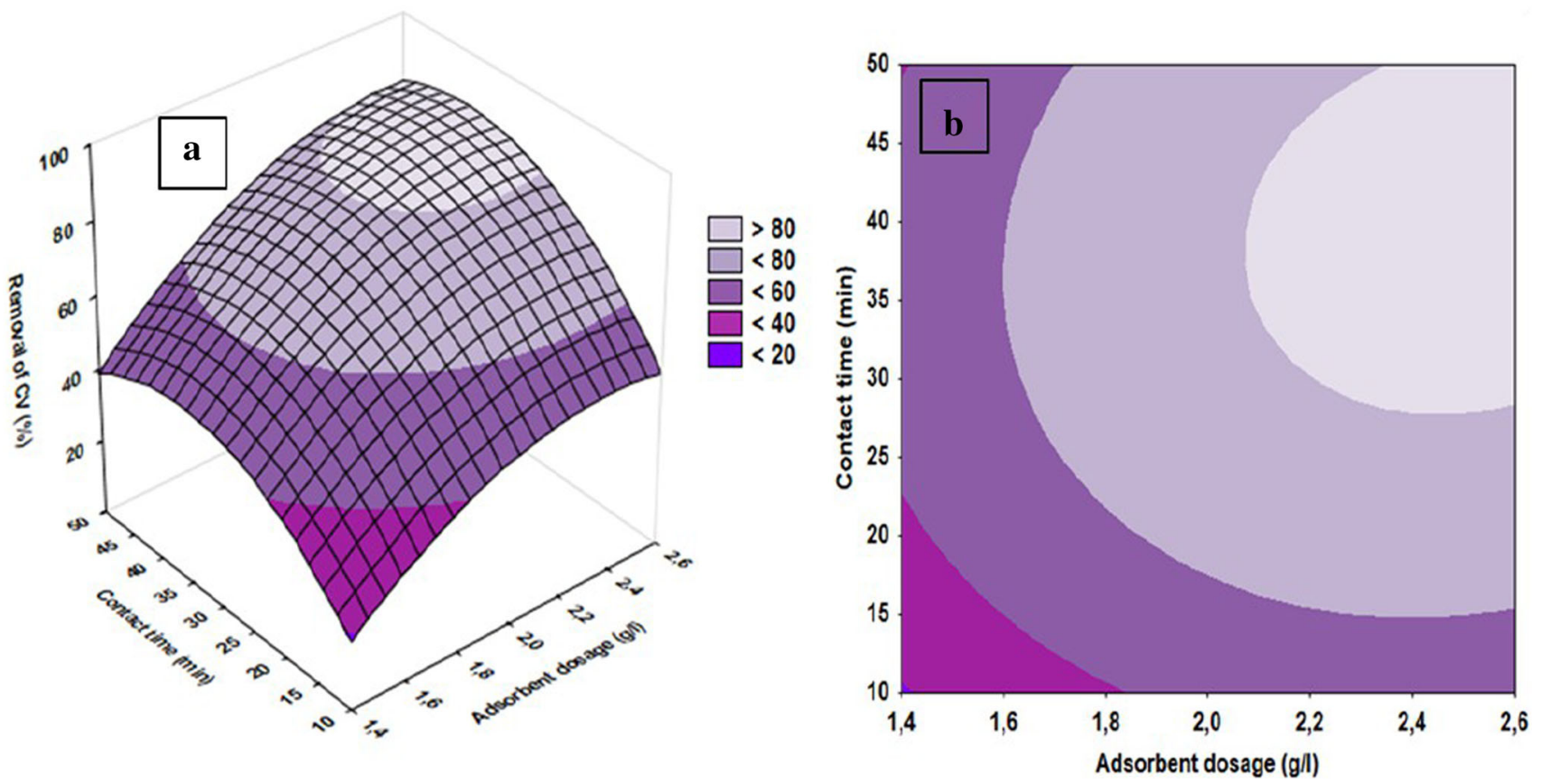

Fig. 9 The response surface plot (a) and corresponding counter plot (b) for the interactive effect of adsorbent dosage and contact time

and $X_{3}^{2}$ ). The graphical response surface plot demonstrated that the initial dye concentration is the most significant component of the quadratic model for the present adsorbent-adsorbate system. Optimization conditions for the maximum removal efficiency of $\mathrm{CV}$ were obtained by applying a desirability function in RSM. The level of the three variables, initial dye concentration $125 \mathrm{mg} \mathrm{L}^{-1}$, adsorbent dose $2.5 \mathrm{~g} \mathrm{~L}^{-1}$, contact time $43 \mathrm{~min}$, were found to be optimum for maximum $\mathrm{CV}$ removal. The corresponding removal efficiency in optimum conditions was found to be $81.62 \%$ for the above conditions of operational parameters. Practically, the (\%) removal is in the range of 27.42-95.30\%. Conclusively, the Box-Behnken model is suitable to optimize the experiments for dye removal by 

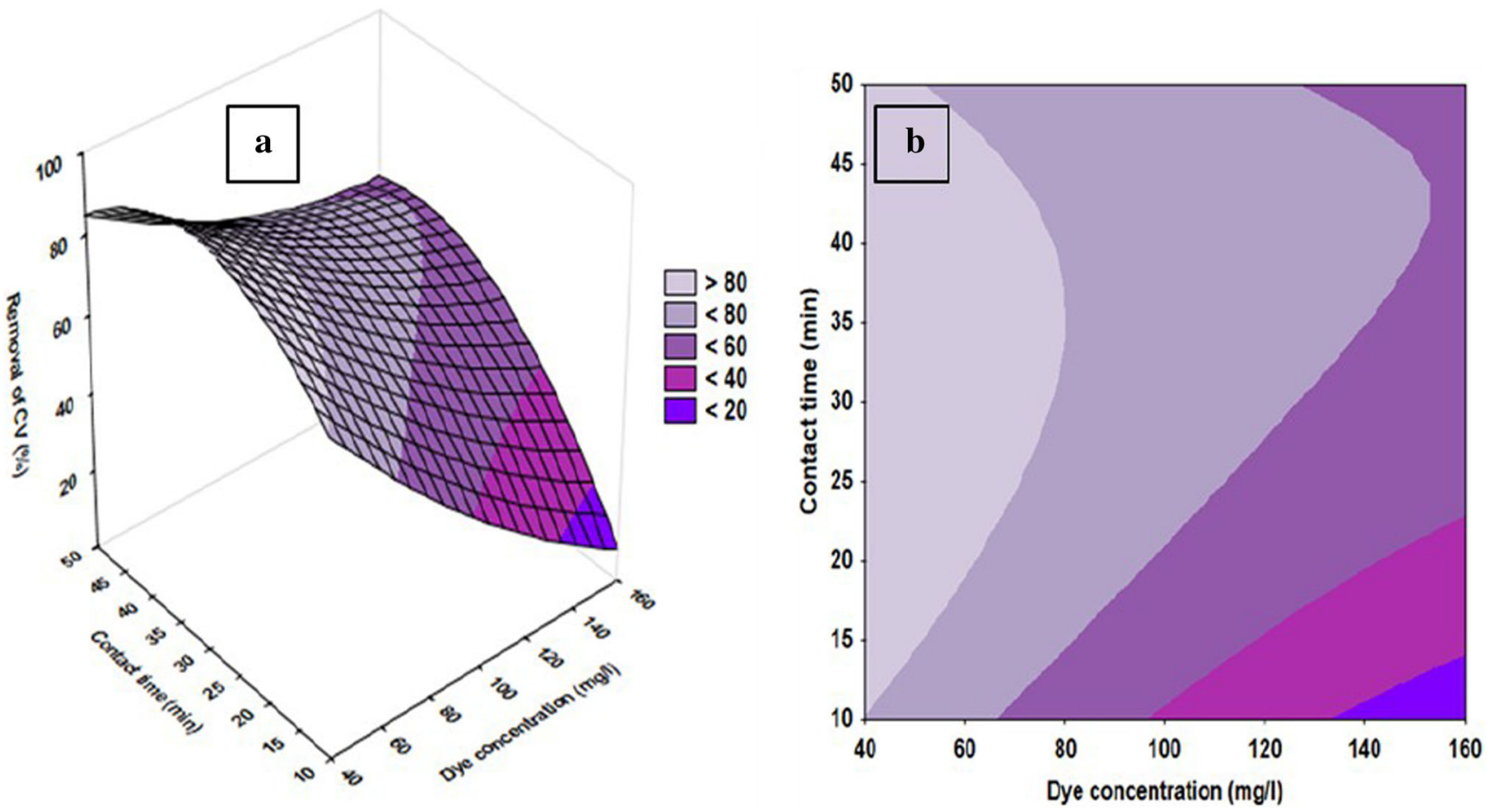

Fig. 10 The response surface plot (a) and corresponding counter plot (b) for the interactive effect of dye concentration and contact time

adsorption, where the local clay would be an efficient adsorbent for treating CV solution. Particle Size Analyzer was used to determine the granulometric parameters $d_{10}$, $d_{50}$ and $d_{90}$ of the local clay. The cumulative and differential particle size distributions of this material are 2.10, 25.47 and $110.10 \mu \mathrm{m}$, respectively, for $d_{10}, d_{50}$ and $d_{90}$.

Acknowledgements The authors would thank Laboratory Civil engineering and Environmental, School of the mines of Douai, Douai (France) for particle size analysis. We also thank E. Soballa (KITINE) for ESEM and EDX analysis and Tanja Kisely for determination of the specific surface area and for collecting the gas adsorption data.

Open Access This article is distributed under the terms of the Creative Commons Attribution 4.0 International License (http:// creativecommons.org/licenses/by/4.0/), which permits unrestricted use, distribution, and reproduction in any medium, provided you give appropriate credit to the original author(s) and the source, provide a link to the Creative Commons license, and indicate if changes were made.

\section{References}

Adinarayana K, Ellaiah P (2002) Response surface optimization of the critical medium components for the production of alkaline protease by a newly isolated Bacillus sp. J Pharm Sci 5:272-278

Ahmad R (2009) Studies on adsorption of crystal violet dye from aqueous solution onto Coniferous pinus bark powder (CPBP). J Hazard Mater 171:767-773

Ahmaruzzaman M (2010) A review on the utilization of fly ash. Prog Energy Combust Sci 36:327-363
Ali I (2012) New generation adsorbents for water treatment. Chem Rev 112:5073-5091

Ali I, Gupta VK (2006) Advances in water treatment by adsorption technology. Nat Protoc 1:2661-2667

Amenaghawon NA, Nwaru KI, Aisien FA, Ogbeide SE, Okieimen CO (2013) Application of Box-Behnken design for the 3 optimization of citric acid production from corn 4 starch using Aspergillus niger. Br Biotechnol J 3:236-245

Aziz F, Rehman MSU, Batool A, Muhammad A, Mahmood T (2012) Pretreatment of municipal, industrial and composite wastewater by ozonation. Environ Process Eng 1-2:1-8

Chen $\mathrm{CH}$, Chang CF, Ho CH, Tsai TL, Liu SM (2008) Biodegradation of crystal violet by a Shewanella sp. NTOU1. Chemosphere 72:1712-1720

Chowdhury S, Mishra R, Saha P, Kushwaha P (2011) Adsorption thermodynamics, kinetics and isosteric heat of adsorption of malachite green onto chemically modified rice husk. Desalination 265:159-168

Chowdhury S, Chakraborty S, Saha PD (2013) Response surface optimization of a dynamic dye adsorption process: a case study of crystal violet adsorption onto $\mathrm{NaOH}$-modified rice husk. Environ Sci Pollut Res 20:1698-1705

Daniel M, Luna G, Flores ED, Genuino DAD, Futalan CM, Wan MW (2013) Eriochrome Black T (EBT) dye using activated carbon prepared from waste rice hulls-Optimization, isotherm and kinetic studies. J Taiwan Inst Chem Eng 44:646-653

Deniz F, Saygideger SD (2010) Investigation of adsorption characteristics of Basic Red 46 onto gypsum: Equilibrium, kinetic and thermodynamic studies. Desalination 262:161-165

Feng Y, Yang F, Wang Y, Ma L, Wu Y, Kerr PG (2011) Basic dye adsorption onto an agro-based waste material-sesame hull (Sesamum indicum L.). Bioresour Technol 102:10280-10285

Gupta VK, Agarwal S, Saleh TA (2011) Synthesis and characterization of alumina-coated carbon nanotubes and their application for lead removal. J Hazard Mater 185:17-23 
Hamsaveni DR, Prapulla SG, Divakar S (2001) Response surface methodological approach for the synthesis of isobutyl butyrate. Process Biochem 36:1103-1109

Hao OJ, Kim H, Chiang PC (2000) Decolorization of wastewater. Environ Sci Technol 30:449-505

Hasan SH, Srivastava P, Talat M (2009) Biosorption of Pb(II) from water using biomass of Aeromonas hydrophila: central composite design for optimization of process variables. J Hazard Mater 168:1155-1162

Hassani A, Khataee A, Karaca S, Karacaa M, Kıranşan M (2015) Adsorption of two cationic textile dyes from water with modified nanoclay: a comparative study by using central composite design. JECE 3:2738-2749

Hazrat A, Shah KM (2008) Biosorption of crystal violet from water on leaf biomass of calotropis procera. J Env Sci Technol $1: 143-150$

Iliescu RI, Andronescu E, Ghitulica CD, Voicu G, Ficai A, Hoteteu M (2014) Montmorillonite-alginate nanocomposite as a drug delivery system-incorporation and in vitro release of irinotecan. Int J Pharm 463:184-192

Javaid M, Saleemi AR, Naveed S, Zafar M, Ramzan N (2011) Anaerobic treatment of desizing effluent in a mesophilic anaerobic packed bed reactor. J Pak Inst Chem Eng 39:61-67

Khajeh M (2009) Application of Box-Behnken design in the optimization of a magnetic nanoparticle procedure for zinc determination in analytical samples by inductively coupled plasma optical emission spectrometry. J Hazard Mater 172:385-389

Khani H, Rofouei MK, Arab P, Gupta VK, Vafaei Z (2010) Multiwalled carbon nanotubes-ionic liquid-carbon paste electrode as a super selectivity sensor: application to potentiometric monitoring of mercury ion(II). J Hazard Mater 183:402-409

Khataee AR, Dehghan G (2011) Optimization of biological treatment of a dye solution by macroalgae Cladophoora sp. using response surface methodolofy. J Taiwan Inst Chem Eng 42:26-33

Khataee AR, Zarei M, Ordikhani-Seyedlar R (2011) Heterogeneous photocatalysis of a dye solution using supported $\mathrm{TiO}_{2}$ nanoparticles combined with homogeneous photoelectrochemical process: molecular degradation products. J Mol Catal A Chem 338:84-91

Khataee AR, Naseri A, Zarei M, Safarpour M, Moradkhannejhad L (2012) Chemometrics approach for determination and optimization of simultaneous photooxidative decolourization of a mixture of three textile dyes. Environ Technol 33:2305-2317

Khayet M, Zahrim AY, Hilal N (2011) Modelling and optimization of coagulation of highly concentrated industrial grade leather dye by response surface methodology. Chem Eng J 167:77-83

Kousha M, Daneshvar E, Sohrabi MS, Koutahzadeh N, Khataee AR (2012) Optimization of CI Acid black 1 biosorption by Cystoseira indica and Gracilaria persica biomasses from aqueous solutions. Int Biodeterior Biodegrad 67:56-63

Kurt E, Koseoglu-Imer DY, Chellam NS, Koyuncu I (2012) Pilotscale evaluation of nanofiltration and reverse osmosis for process reuse of segregated textile dye wash wastewater. Desalination 302:24-32

Liu HL, Lan YW, Cheng YC (2004) Optimal production of sulphuric acid by Thiobacillus thiooxidans using response surface methodology. Process Biochem 39:1953-1961

Lotito AM, Fratino U, Bergna G, Iaconi CD (2012) Integrated biological and ozone treatment of printing textile wastewater. Chem Eng J 195-196:261-269

Mane VS, Babu PVV (2011) Studies on the adsorption of Brilliant Green dye from aqueous solution onto low-cost $\mathrm{NaOH}$ treated saw dust. Desalination 273:321-329

Marshall TJ, Holmes JW, Rose CW (1996) Soil Physics, 3rd edn. Cambridge University Press
Mass R, Chaudhari S (2005) Adsorption and biological decolourization of azo dye Reactive Red-2 in semi continuous anaerobic reactors. Process Biochem 40:699-705

Mittal A, Kaur D, Malviya A, Mittal J, Gupta VK (2009a) Adsorption studies on the removal of coloring agent phenol red from wastewater using waste materials as adsorbents. J Colloid Interface Sci 337:345-354

Mittal A, Mittal J, Malviya A, Gupta VK (2009b) Adsorptive removal of hazardous anionic dye "Congo red" from wastewater using waste materials and recovery by desorption. J Colloid Interface Sci 340:16-26

Mittal A, Mittal J, Malviya A, Kaur D, Gupta VK (2010) Decoloration treatment of a hazardous triarylmethane dye, Light Green SF (Yellowish) by waste material adsorbents. J Colloid Interface Sci 342:518-527

Mittal A, Thakur V, Gajbe V (2012a) Evaluation of adsorption characteristics of an anionic azo dye brilliant yellow onto hen feathers in aqueous solutions. Environ Sci Pollut Res 19:2438-2447

Mittal A, Thakur V, Gajbe V (2012b) Adsorptive removal of toxic azo dye Amido Black 10B by hen feather. Environ Sci Pollut Res 20:260-269

Muhamad MH, Abdullah SRS, Mohamad AB, Rahman RA, Kadhum AAH (2013) Application of response surface methodology (RSM) for optimisation of COD NH3-N and 2, 4-DCP removal from recycled paper wastewater in a pilot scale granular activated carbon sequencing batch biofilm reactor (GAC-SBBR). J Environ Manag 121:179-190

Murray H (2000) Traditional and new applications for kaolin, smectite, and palygorskite: a general overview. Appl Clay Sci 17:207-221

Myers RH, Montgomery DC (2002) Response surface methodology: process and product optimization using designed experiments, 2nd edn. Wiley, New York

Nandi BK, Goswami A, Purkait MK (2009) Adsorption characteristics of brilliant green dye on kaolin. J Hazard Mater 161:387-395

Padilla-Ortega E, Leyva-Ramos R, Flores-Cano JV (2013) Binary adsorption of heavy metals from aqueous solution onto natural clays. Chem Eng J 225:535-546

Poroch-Seritan M, Gutt S, Gutt G, Cretescu I, Cojocaru C, Severin T (2011) Design of experiments for statistical modeling and multiresponse optimization of nick electroplating process. Chem Eng Res Des 89:136-147

Qian F, Sun X, Liu Y (2013) Removal characteristics of organics in bio-treated textile wastewater reclamation by a stepwise coagulation and intermediate GAC/O3 oxidation process. Chem Eng J 214:112-118

Rauf MA, Shehadeh I, Ahmed A, Al-Zamly A (2009) Removal of methylene blue from aqueous solution by using gypsum as a low cost adsorbent. World Acad Sci Eng Technol 31:604-609

Rehman MSU, Kim I, Han JI (2012) Adsorption of methylene blue dye from aqueous solution by sugar extracted spent rice biomass. Carbohydr Polym 90:1314-1322

Rehman MSU, Kim I, Han JI (2013) Biosorption of methylene blue from aqueous solutions by Typha angustata phytomass. Int J Environ Sci Technol 10:865-870

Roulia M, Vassiliadis AA (2005) Interactions between C.I. Basic Blue 41 and aluminosilicate sorbents. J Colloid Interface Sci 291:37-44

Saleh TA, Gupta VK (2012) Processing photo-catalyzed degradation of hazardous dye methyl orange by use of a composite catalyst consisting of multi-walled carbon nanotubes and titanium dioxide. J Colloid Interface Sci 371:101-106

Santhy K, Selvapathy P (2006) Removal of reactive dyes from wastewater by adsorption on coir pith activated carbon. Bioresour Technol 97:1329-1336

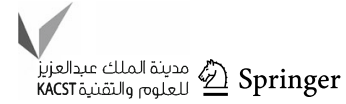


Sen R, Swaminathan T (2004) Response surface modeling and optimization to elucidate and analyze the effects of inoculum age and size on surfactin production. Biochem Eng J 21:141-148

Shakeel F, Haq N, Alanazi FK, Alsarra IA (2014) Box-Behnken statistical design for removal of methylene blue from aqueous solution using sodium dodecyl sulfate self-microemulsifying systems. Ind Eng Chem Res 53:1179-1188

Sharma P, Kaur H, Sharma M, Shahore V (2011) A review of applicability of naturally available adsorbents for the removal of hasardous dyes from aqueous waste. Environ Monot Assess 183:151-195

Soltani RDC, Rezaee A, Godini H, Khataee AR, Hasanbeiki A (2013) Photoelectrochemical treatment of ammonium using seawater as a natural supporting electrolyte. Chem Ecol 29:72-85

Soltani RDC, Rezaee A, Khataee AR, Godini H (2014) Optimisation of the operational parameters during a biological nitrification process using response surface methodology. Can J Chem Eng 92:13-22
Wu D, Zhou J, Li Y (2009) Effect of the sulfidation process on the mechanical properties of a $\mathrm{CoMoP} / \mathrm{Al}_{2} \mathrm{O}_{3}$ hydrotreating catalyst. Chem Eng Sci 64:198-206

Yasar A, Khalil S, Tabinda AB, Malik A (2013) Comparison of cost and treatment efficiency of solar assisted advance oxidation processes for textile dye bath effluent. Korean J Chem Eng 30:131-138

Yetilmezsoy K, Demirel S, Vanderbei RJ (2009) Response surface modeling of $\mathrm{Pb}$ (II) removal from aqueous solution by Pistacia vera L.: Box-Behnken experimental design. J Hazard Mater 171:551-562

Zarei M, Niaei A, Salari D, Khataee A (2010) Application of response surface methodology for optimization of peroxi-coagulation of textile dye solution using carbon nanotube-PTFE cathode. J Hazard Mater 173:544-551 